\title{
Experimental investigation of the processes of dehumidification of coniferous biomass
}

\author{
Elena Bulba $^{1 *}$, and Natalya Ivanova $^{1}$ \\ ${ }^{1}$ National Research Tomsk Polytechnic University, 634050 Tomsk, Russia
}

\begin{abstract}
This work includes the results of experimental studies of the moisture removal processes in the temperature range from $333 \mathrm{~K}$ to $413 \mathrm{~K}$ from coniferous woods which are typical for many regions. There are obtained the dependences of the mass rate of moisture removal on time and temperature. The effect of the evaporation of bound moisture was identified for the wood species studied. There are calculated the accommodation coefficient and the partial pressure at the evaporation surface for each type of biomass.
\end{abstract}

\section{Introduction}

The preparation of wood biomass for burning is an energy-consuming process due to the fact that it is always more or less saturated with moisture [1-3] because of its high porosity. Though, the calculation of the characteristics of the moisture output from porous materials is very complicated. The description of the processes of the evaporation front motion from the surface of the heated material to its deep layers is currently being carried out in many cases (for example, [4-5]) using the mathematical expression of the Hertz-KnudsenLangmuir law [6-7]. That is why it is necessary to know the accommodation coefficient, which is not a constant value and in each specific case it depends on the heating and outflow conditions of the liquid vapor (for example, [4-5]) from the surface of the phase transformations. The definition of this characteristic in all cases of its using is a complex task, which is solved in the course of experimental studies. Therefore, the study of regularities in the processes of moisture removal is one of the main tasks in the development of technologies for burning biofuel in furnaces of steam and hot water boilers [2].

\section{Experiment, results and discussion}

There were studied the samples of coniferous species of wood, which are most common in the territory of Siberia: pine, spruce, cedar, fir. The methodology of the experiment was previously described in detail in [8-9].

\footnotetext{
*Corresponding author: bulba@tpu.ru
} 
After the experimental determination of the evaporated during the time interval $\Delta t$ moisture mass in a drying chamber was found the mass flow rate of dehumidification of fluid from the sample studied wood

$$
W=\frac{\Delta m}{s \cdot \Delta t},
$$

where $W$ - the mass flow rate of dehumidification, $\mathrm{kg} /\left(\mathrm{m}^{2} \mathrm{~s}\right) ; \Delta m$ - the change in the mass of sample, $\mathrm{kg} ; S$ - the surface area of the evaporation $\left(S=0.0227 \mathrm{~m}^{2}\right) ; \Delta t$ is the drying time.

According to the obtained values of $W$ there are constructed the dependences of the mass rate of dehumidification on time and temperature, which are presented in Figures 1-5. Vertical bars are confidence intervals determining $W$.

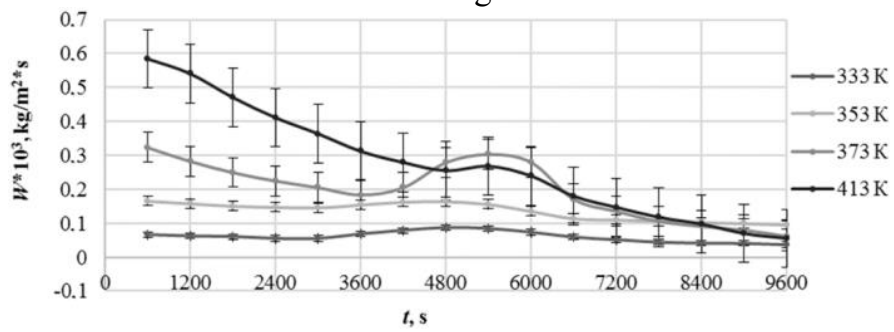

Fig. 1. Dependences of the mass evaporation rate on time for cedar.

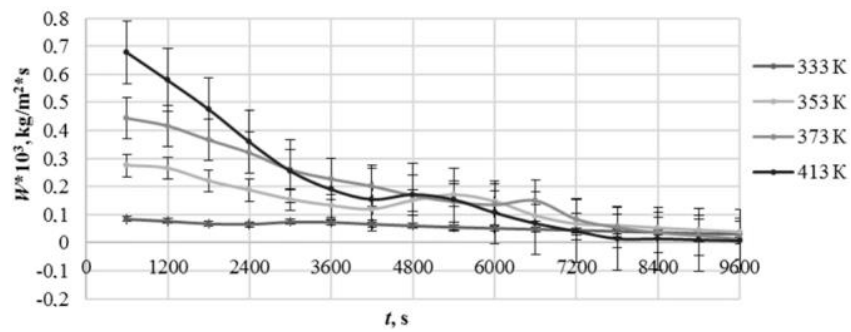

Fig. 2. Dependences of the mass evaporation rate on time for fir.

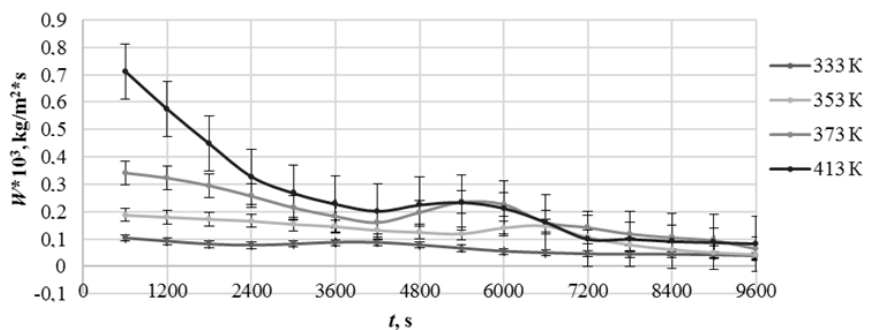

Fig. 3. Dependences of the mass evaporation rate on time for eat.

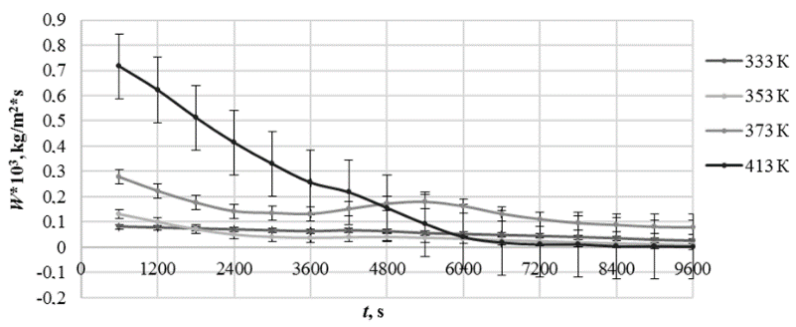

Fig. 4. Dependences of the mass evaporation rate on time for pine. 
As can be seen from the obtained dependences in the temperature range $333-353 \mathrm{~K}$, the process of removal of bound moisture does not begin for 9600 seconds. At temperatures of $373-413 \mathrm{~K}$ the evaporation rate decreases during the time interval of about 60 minutes is the first drying period. It corresponds to the removal of free moisture, distributed in the pores of the material. Then begins the process of removal of bound moisture. This period lasts for about 2 hours. The increase in evaporation rate before the onset of the second period is explained by the fact that free and bound moisture begin to evaporate together and this increases the overall evaporation rate.

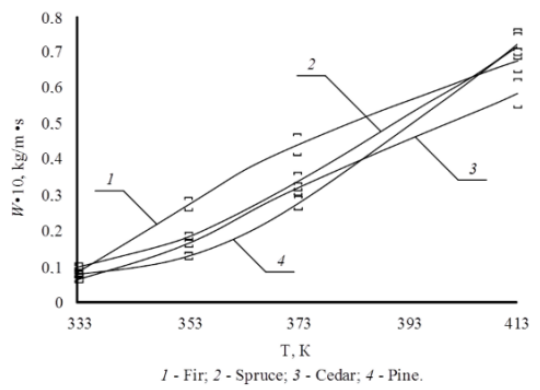

Fig. 5. Dependence of the mass evaporation rate on temperature

The analysis of the received dependences showed that the highest rate of dehumidification corresponds to the fir. This is due to the fact that the density of this wood is lower than the density of the other samples (spruce 15\% pine and $25 \%$ ). Accordingly, pores occupy the largest part in the structure of this breed of coniferous trees, in comparison with the other parts. So water vapor with less resistance comes to the heating surface. It is installed that the pine has the lowest rate of dehumidification as it corresponds to a higher density in comparison with the other materials. It can be concluded that the drying of fir and spruce occur with less time and energy costs.

The accommodation coefficient and partial pressure were determined using the experimental results and kinetic theory equation of Hertz-Knudsen [7].

$$
W=\frac{A \cdot\left(P-P^{*}\right)}{\sqrt{\frac{2 \pi R T}{M}}},
$$

where $P$ - saturated vapor pressure, $\mathrm{PA} ; P^{*}$ - partial pressure, $\mathrm{PA} ; R$ - universal gas constant, $R=8314 \mathrm{~J} / \mathrm{Kmol} \cdot \mathrm{K} ; M$ - molecular mass of moist air, $T$ - temperature, $\mathrm{K} ; A$ coefficient of accommodation.

In equation (2) for two unknowns - the accommodation coefficient and the partial pressure.

The second equation, which allows to close the system and calculate the partial pressure and the accommodation coefficient is the equation of state.

$$
P_{a} \cdot V=\left(m_{1}+m_{2}\right) \cdot \frac{R}{M} \cdot T,
$$

where $P_{a}$ - pressure of humid air, which is assumed equal to atmospheric, $P_{a}=101325$ PA; $V$ - volume of drying chamber, $V=0,36 \mathrm{~m}^{3} ; m_{1}$ - mass of dry air, $\mathrm{kg} . m_{2}$ - mass of water vapor, $\mathrm{kg}$.

The molecular mass of moist air is present in the form of the expression.

$$
M=\frac{m_{1}+m_{2}}{\frac{m_{1}}{M_{1}}+\frac{m_{2}}{M_{2}}}
$$


where $M_{1}$ is the molecular mass of dry air, $M_{1}=29 \mathrm{~g} / \mathrm{mol} ; M_{2}-$ molecular weight of water vapor, $M_{2}=18 \mathrm{~g} / \mathrm{mol}$.

Solving the system of equations (3) and (4) we obtain the expression for the mass of dry air.

$$
m_{1}=\left[\frac{P_{a} \cdot V}{R \cdot T}-\frac{m_{2}}{M_{2}}\right] \cdot M_{1} .
$$

The total mass of moisture evaporated from the sample, determined by knowing the mass of moist air at the initial moment of time in the drying chamber.

$$
m_{2}^{0}=d \cdot m_{1}^{0},
$$

where $\mathrm{d}$ - moisture content of moist air; $m_{1}^{0}$ - mass of dry air in the chamber at the initial moment of time.

From the equation of state of an ideal gas calculate the moisture content of moist air.

$$
d=0,622 \cdot \frac{(\varphi \cdot P)}{P_{a}-(\varphi \cdot P)},
$$

where $\varphi$ - relative humidity at the time of the experiment (40\%).

The mass of dry air in the chamber determined from the following expression:

$$
m_{1}^{0}=V \cdot \rho,
$$

where $\rho$ - density of dry air, $\mathrm{kg} / \mathrm{m}^{3}$.

The density of the dry air in the room determined by the formula:

$$
\rho=\frac{P_{a}-\varphi \cdot P}{\frac{R}{M} \cdot T} .
$$

Then we find the total mass of water vapor in the chamber.

$$
m_{2}=\Delta m+m_{2}^{0} \text {. }
$$

From equations (3) and (5) we Express the molecular weight of moist air.

$$
M=\frac{m_{2}+\left[\frac{P a \cdot V}{R \cdot T}-\frac{m_{2}}{M_{2}}\right] \cdot M_{1}}{\frac{m_{2}}{M_{2}}+\frac{P a \cdot V}{R \cdot T}-\frac{m_{2}}{M_{2}}}=\frac{m_{2}+\left[\frac{P a \cdot V}{R \cdot T}-\frac{m_{2}}{M_{2}}\right] \cdot M_{1}}{\frac{P a \cdot V}{R \cdot T}}
$$

Find the volume and mass fraction of water vapor:

- mass fraction of water vapor

$$
g=\frac{m_{2}}{m_{2}+\left[\frac{P a^{\cdot V}}{R \cdot T}-\frac{m_{2}}{M_{2}}\right] \cdot M_{1}} ;
$$

- volume fraction of water vapor

$$
r=\frac{g \cdot M}{M_{2}}
$$

Knowing the volume fraction of evaporated moisture and vapor pressure, we find the partial pressure at the surface of evaporation at the dripping for each type of biomass

$$
P^{*}=r \cdot P \text {. }
$$


Then we determine the values of the accommodation coefficient in the appropriate temperature range for all studied materials, using the Hertz-Knudsen equation (2).

\section{Conclusion}

According to the results of the experimental studies of moisture removal processes typical of many regions of coniferous species of wood in the temperature range from $333 \mathrm{~K}$ to 413 $\mathrm{K}$, there were established the dependences of the mass rate of moisture removal on time and temperature for four species of wood. There was proposed a method for calculating the accommodation coefficient and partial pressures at the evaporation surface for each type of wood.

The established regularities can be used with further refinement of the mechanism of moisture removal from the porous structure of moisture-containing materials and development of the general theory of drying. Also, the results of the research can be used in testing mathematical models for drying woody biomass.

Another possible application of the experimental data obtained can be their use in analyzing the processes of gas cleaning from wet wood waste (for example, [10-11]).

\section{References}

1. T. Nussbaumer, Proc. of the 10th Europ. Bioenergy Conf., 11421145 (1998)

2. Y. Solantausta, 8th EC Conf., Vienna, Austria, 2, 1579-1591 (1994)

3. H. Dienhart, Proc. of the 10th Europ. Bioenergy Conf., 1460-1463 (1998)

4. S.V. Syrodoy, G.V. Kuznetsov, V.V. Salomatov, Thermal Engineering, 62, A002 (2015), DOI: 10.1134/S0040601515100092

5. G.V. Kuznetsov, V.V. Salomatov, S.V. Syrodoy, Combust. Explos., 51, 4 (2015), DOI: 10.1134/S0010508215040024

6. V.L. Strakhov, A.N. Garashchenko, G.V. Kuznetsov, V.P. Rudzinskii, Combust. Explos., 37, 2 (2001), DOI: 10.1023/A:1017557726294

7. G.V. Kuznetsov, P.A. Kuybin, P.A. Strizhak, High Temp., 53, 2 (2015), DOI: 10.1134/S0018151X15020133

8. E.E. Bulba, A.A. Malinovsky, MATEC Web of Conferences, 23, 01053 (2015), DOI: 10.1051/matecconf/20152301053

9. EE Bulba, N.A. Ivanova, MATEC Web of Conferences, 110, 01020 (2017), DOI: 10.1051/matecconf/201711001020

10. M.V.Vasilevsky, E.G.Zykov, A.S.Razva, Theoretical Foundations of Chemical Engineering, 45, 3 (2011), DOI: 10.1134/S0040579511030146

11. A.S. Razva, M.V. Vasilevsky, V. Rykov, MATEC of Conferences, 23, 01035 (2015), DOI: 10.1051/matecconf/20152301035 